\title{
As matrizes antigas da crítica historiográfica de Francesco Patrizi nos primeiros Dialoghi della historia (Veneza, I560)
}

\author{
The Ancient Sources for Francesco Patrizi’s Historiographical Criticism in the first \\ Dialoghi della historia (Venice, I560)
}

\section{Helvio Moraes"}

Resumo: Propomos uma leitura de três dos Diece Dialoghi della Historia de Francesco Patrizi da Cherso, em que o filósofo desenvolve as principais ideias de sua concepção historiográfica. Tais diálogos constituem a pedra angular da obra, em sua negação de concepções clássicas da História (Dialogo Primo - Il Gigante, overo dell'historia); em sua tentativa de alargar ao máximo o campo da investigação histórica (Dialogo Secondo - Il Bidernuccio, overo della diversità dell'historia); e, por fim, na filiação a certos pressupostos platônicos (Dialogo Terzo - Il Contarino, overo che sia l'historia) que lançam as bases de uma teoria da História que terá ressonâncias no pensamento de intelectuais como Bodin e Vico. Busco identificar, na tradição greco-romana, as matrizes de certas ideias com as quais Patrizi opera na construção deste alicerce, e o modo como o faz.

Palavras-chave: ars historica; historiografia; neoplatonismo renascentista; Francesco Patrizi da Cherso

\begin{abstract}
This study is aimed at the analysis of three of Francesco Patrizi da Cherso's Diece Dialoghi della Historia, in which the philosopher develops the main ideas of his historiographic conception. These dialogues constitute the work's cornerstone, given the denial of classical conceptions of History (Dialogo Primo - Il Gigante, overo dell'historia); the endeavor to greatly

\footnotetext{
"Professor do Programa de Pós-Graduação em Estudos Literários (PPGEL) da Universidade do Estado de Mato Grosso - Unemat; Co-editor da revista Morus - Utopia e Renascimento; Pesquisador do CNPq - Conselho Nacional de Desenvolvimento Científico e Tecnológico.
} 
expand the field of historical investigation (Dialogo Secondo - Il Bidernuccio, overo della diversità dell'historia); and, lastly, the assumption of certain platonic tenets (Dialogo Terzo - Il Contarino, overo che sia l'historia) that set the basis for a theory of History which will resound in the works of some thinkers, such as Bodin and Vico. I try to verify, in the Greek-Roman tradition, the sources of certain ideias with which Patrizi operates in developing this basis, as well as the way he does it.

Keywords: ars historica; historiography; Renaissance neoplatonism; Francesco Patrizi da Cherso

Minha proposta, neste estudo, é fazer uma leitura de três dos Diece Dialoghi della Historia de Francesco Patrizi da Cherso (I529-I597), justamente os três primeiros, em que o filósofo desenvolve as principais ideias de sua concepção historiográfica. Tais diálogos constituem a pedra angular da obra, em sua negação de concepções clássicas da História (Dialogo Primo - Il Gigante, overo dell'historia); em sua tentativa de alargar ao máximo o campo da investigação histórica (Dialogo Secondo - Il Bidernuccio, overo della diversità dell'historia); e, por fim, na filiação a certos pressupostos platônicos (Dialogo Terzo - Il Contarino, overo che sia l'historia), a partir dos quais são lançadas as bases de uma teoria da História que terá ressonâncias no pensamento de intelectuais como Bodin e Vico. Buscarei identificar, na tradição greco-romana, as matrizes de certas ideias com as quais Patrizi opera na construção deste alicerce, e o modo como o faz.

Os Diálogos da historia foram escritos ainda na juventude do filósofo, quando encontrava-se em Veneza. Sua publicação data de I560, momento imediatamente anterior a sua ida a Chipre, onde permaneceu por alguns anos em cargos administrativos, representando os interesses do conde Giorgio Contarini e do arcebispo Filippo Mocenigo. Durante sua "estada" veneziana, que deve ter durado cerca de cinco anos, Patrizi estabeleceu estreitas relações com vários intelectuais e patrícios da cidade lagunar, e participou ativamente das 
atividades desenvolvidas no interior da Accademia Veneziana, ou Accademia della Fama ${ }^{I}$, como se tornou mais conhecida na posteridade. Além disto, esteve envolvido diretamente com a indústria editorial de Veneza. O ambiente intelectual no interior da Accademia serviu como um meio de amadurecimento de seu pensamento filosófico não ortodoxo (ao menos em relação à tradição filosófica preponderante na Universidade de Pádua) ${ }^{2}$. Seu neoplatonismo o fará dirigir uma crítica corrosiva às auctoritates e, por meio delas, aos métodos historiográficos nos moldes dos humanistas do Quattrocento, na tentativa de elaborar uma nova teoria da História, não mais vinculada aos três gêneros da Retórica, "mas por via da ciência, das causas e dos princípios primeiros do falar"3.

De fato, é muito provável que, simultaneamente à escrita dos Dialoghi della historia, Patrizi prepara também seus dez Dialoghi della retorica, que, no entanto, serão publicados somente dois anos depois. Há uma grande conformidade entre os dois textos, que, obviamente, condiz com a forma que a ambos encerra, mas que também se encontra em suas proposições centrais. $\mathrm{O}$ tom que os permeia é o de insatisfação quanto às investigações e modelos metodológicos avançados pelas auctoritates e ao modo como são adotados por seus contemporâneos, sem uma análise profunda de seu significado e de suas limitações. Em ambos os textos, Patrizi desloca esta forma de abordagem da problemática referente aos dois campos do conhecimento, buscando, primeiramente, defini-los de forma precisa, o que o leva a passar em revista os enunciados tradicionais, apontando seus limites e, consequentemente, alargando o campo de tais conceitos. Neste alargamento talvez esteja implícito o maior contributo do filósofo para novas formas de se conceber a história e a retórica, permitindo que se contemplem elementos até então mantidos fora do alcance da reflexão acerca das duas disciplinas.

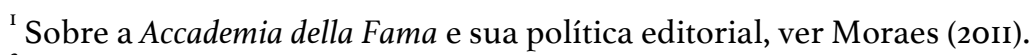

${ }^{2}$ Conforme sugere Vasoli (I99I, p. I56), "a relação com a Accademia e com os intelectuais que a freqüentavam foi particularmente importante, não somente e não tanto porque confirmou sua predileção por uma tradição filosófica de predominante 'aura' platônica, mas acima de tudo porque Patrizi encontrou-se envolvido em um ousado programa cultural que buscava obter para esta instituição o papel de guia 'oficial' da vida cultural veneziana, em inevitável contraste com as tendências dominantes no Studio paduano [...]"

${ }^{3}$ Francesco Patrizi da Cherso, Dialoghi della historia, A2r (por serem muitas as citações da obra, a partir daqui as referências das páginas virão entre parênteses, no corpo do texto). Creio que Patrizi tenha em mente, além de trechos do Gorgias e do Sofista, principalmente as ideias centrais do Fedro, como as passagens entre 259e-263b, em que Platão afirma que a verdadeira arte de produzir discursos deve fundamentar-se no conhecimento da verdade, ou seja, na filosofia, e não na opinião.
} 
Boa parte dos estudiosos da obra patriziana aponta para o aspecto demolidor dos primeiros diálogos. Não acredito que seja casual o primeiro diálogo, Il Gigante overo della historia, abrir com uma cena de deslocamento. Um pequeno grupo de gentis-homens saem, após ouvirem a missa, de uma igreja situada num sestiere mais afastado de Veneza e lentamente se encaminha para o centro político e administrativo da república, San Marco, discorrendo sobre a história ${ }^{4}$. Narrada por Patrizi a dois interlocutores, Alfonso Bidernuccio e Giovanni Gigante, a cena o impressionara pela novidade da argumentação, pela qual pudera experimentar um "incrível deleite e proveito" (Ir).

Este entusiasmo fornece a ocasião para que surja imediatamente um elogio da história, feito por Bidernuccio:

coisa sobremodo bela e útil [...], com que todo homem civil, todo senador e todo príncipe deveria, com grande estudo, deleitar-se e se familiarizar, posto que é repleta de toda forma de vida, boa ou má, [...] na qual, como num espelho, ou, mais verdadeiramente, num teatro, pode-se ver todas as coisas humanas e todos os seus felizes e desventurados acontecimentos (Ir).

É justamente a partir desta visão encomiástica da história que Patrizi passará ao "desmantelamento" daquelas concepções que tenham algum débito com os preceitos da retórica tradicional, principalmente as que seguem as linhas de autoridades como Cícero e Luciano. No caso de Cícero, algumas de suas ideias sobre a história serão expostas com a finalidade de se provar como não resistem a uma análise mais profunda, por serem ambíguas ou superficiais. Patrizi rápida e ironicamente se desembaraça delas, convicto de que em nada contribuem para uma definição da história. Neste diálogo, duas serão as máximas ciceronianas afrontadas: a primeira encontra-se no De Inventione, I. $27^{5}$ e também na Rethorica ad Herennium, I.I3, que acreditava-se, na época, fosse de autoria do orador romano. Bidernuccio a apresenta, afirmando que a "história é uma ação realizada, remota da memória

\footnotetext{
${ }^{4}$ Leio este momento inicial como uma imagem altamente alusiva à proposta central destes diálogos, no sentido de que a discussão sobre a história deve se "deslocar" em direção à sua utilidade como um instrumento legítimo para a condução dos assuntos do Estado (que é a proposta dos diálogos finais), da mesma forma como o grupo de gentis-homens, discorrendo sobre a história, se encaminham para San Marco.

5 "Historia est gesta res, sed ab aetis nostrae memoria remota."
} 
de nossos tempos" (Iv). Patrizi se opõe à noção de que a história abranja somente realizações humanas, pois, neste caso, como classificar a História dos Animais de Aristóteles e a História Natural de Plínio, o Velho, por exemplo? Da mesma forma, não se pode dizer que estas obras versem sobre fatos acontecidos em tempos remotos, o que também se dá com as recentes guerras italianas, que já haviam sido relatadas por alguns historiadores.

O segundo enunciado ciceroniano é reelaborado por Gigante a partir de uma passagem da Rhetorica ad Herennium (III, 23), com a afirmação de que a história "é narração de coisas realizadas, da forma como são realizadas”. As lacunas existentes numa definição tão imprecisa como esta, permitem ao filósofo apontar os limites de uma concepção historiográfica que privilegia tão somente as gesta de príncipes e repúblicas, adiantando o tema central do segundo diálogo, ao elencar uma variedade de elementos que parecem estranhos a tal concepção: a história pode abordar temas alheios às ações bélicas, como as navegações dos "portugueses e castelhanos" e "as máquinas que Arquimedes operou nos tempos do assédio de Siracusa", e pode também compreender a biografia de homens ilustres, mas não necessariamente "públicos”, como “as vidas dos santos padres” (2v).

Contestadas as noções ciceronianas, Bidernuccio recorre aos preceitos de Luciano. Porém, diversamente de outros autores de artes historicae, que combinam, às vezes sem muito critério, os lemas de um e as prescrições do outro, Patrizi vislumbra a diferença entre o conceito de história e a práxis historiográfica. Todos os pontos que seu interlocutor avança não dizem respeito ao objeto que o grupo se propusera investigar, ou seja, não concorrem para a formulação do conceito de história, pois estão circunscritos à preceptística que o pensador sírio estabelecera para o registro historiográfico. Em relação a Luciano, portanto, o tratamento de Patrizi é mais pontual, porque busca denunciar a inconsistência de uma normativa que não se constrói a partir da definição do objeto ao qual procura ditar regras.

Sua filiação platônica não consente que a investigação prossiga sem que se defina primeiramente a verdadeira condição daquilo sobre o que se discute. O "o que é?", que se estabelece como a "questão fundamental que preside a conversa dialética socrática", marca também em Patrizi "a exigência de definição, reveladora da capacidade de falar bem e de dizer a verdade" (Rogue, 2002, p. 203). Como em Platão, Patrizi procura distinguir 
aquilo que, na identidade que é pensada, pertence ao seu ser próprio, o que a coisa é nela e por ela mesma e o que pertence ao seu ser relativo, a maneira como ela pode oferecer-se, à vontade, relações infinitas no seio das quais pode ser descrita. A exigência que $O$ que é? socrático formula, o qual inicia a pesquisa da definição, recupera essa distinção. Nas respostas de seus interlocutores, Sócrates afastará sistematicamente o que depende de simples relações feitas da noção, exigindo que se fale do que a coisa é em si mesma. [...] Para se chegar a um logos estável, está claro que é preciso imperativamente remontar ao ser próprio dos objetos que se busca definir (Rogue, 2002, p. 78).

Esta é, a nosso ver, a passagem central deste primeiro diálogo, em que Patrizi determina o princípio metodológico para a apreciação de quaisquer temas que venham a ser introduzidos na discussão acerca da história. Em vários momentos, chegando ao ponto de irritar seus interlocutores, o filósofo repetirá que compreende os argumentos que lhe apresentam, embora não creia que, quanto à história, eles revelem o "que em substância ela seja" (5r).

Neste sentido, muito menos o satisfaz a síntese que Bidernuccio apresenta do Actius de Giovanni Pontano, o diálogo em que o humanista napolitano expressara a ideia de uma forte ligação entre poesia e história, e legara ao historiador a função de explicar e adornar a verdade. De nada adianta querer saber se estas e outras noções ali formuladas satisfazem o “espírito" de Patrizi. Sua proposição já havia sido estabelecida: "não sei o que dizer, dado que não posso saber as qualidades da história antes de saber o que ela seja na verdade" (6r).

\section{III}

A tentativa de abordar filosoficamente a problemática da história a partir de seu conceito é o procedimento que possibilita a Patrizi a subtração em bloco das elaborações em voga no seu tempo. Portanto, não é gratuito que o segundo diálogo, Bidernuccio ou da diversidade da história, se abra com uma descrição irônica da filosofia, um jogo cômico de inversões, em que se nega a importância da vida contemplativa e se considera verdadeiramente sábios aqueles que mais distantes dela se encontram, os ricos e os poderosos, a cujo serviço estão os filósofos, "tolos e estupefatos". Patrizi desenha a imagem da filosofia 
como uma feiticeira que, com seus encantos, faz perder-se o "belo e nobre espírito, [...] ao darlhe de beber a água da ignorância", tornando-o inútil "ao governo dos estados e das cidades", ao perder "o saber e a reputação". Aconselha seus interlocutores, dois advogados, a manterem-se afastados dela, pois de nada lhes valeriam, em seu "belíssimo exercício de falar ante a justiça”, todas as dúvidas com que nos enche o espírito (7r).

O filósofo diz ter sido vítima desta "maga”, o que fez com que seu espírito, cheio de incertezas e confuso, buscando sempre a causa de todas as coisas, termine por confundir também os espíritos daqueles com quem convive. E, com relação ao tema afrontado, sua dúvida maior consiste em não saber encontrar um elemento que traga unidade à enorme diversidade de escritos que se encontram sob a denominação de história: "a razão [...] que sempre me impediu saber o que fosse a história é esta: que percebo serem suas formas infinitas, e infinitamente diferentes entre si, todas as quais, impossível me parece que possam caber numa só definição" (7v).

Assim, à recusa dos limites estabelecidos pela tradição historiográfica precedente (no sentido de que nem só as campanhas militares ou as vidas de homens públicos sejam os temas para os quais se volta o historiador), se contrapõe o "intrincado e tenebroso labirinto" dos mais diversos assuntos, tomados como objetos da narração historiográfica, de todas as épocas ou de nenhuma época específica. Será apresentado um grande elenco de histórias do "mundo maior", que compreende a história natural, os escritos de astronomia, geografia, entre outros, e as histórias do "mundo menor", que narram as ações humanas. Deste modo, não apenas a repúblicas, impérios, príncipes, precisa se ater a narração histórica, mas também a "partes do mundo superior", a fenômenos naturais, a descrições de lugares, às viagens "dos portugueses e dos castelhanos às Índias e ao novo mundo (...), [a] qualidades de certos animais e plantas" (8v-9r), e mesmo a historia minore pode incluir a vida de gramáticos, artistas, camponeses, navegadores, eremitas, assim como "modos de vida [das nações], dos costumes e das leis" (IIr). Em outros diálogos, o tempo também é alargado (pode haver uma história do presente e do futuro, como é o caso das profecias) e, além da narração, são contempladas outras formas de expressão. Para Patrizi, como veremos, a história não é, necessariamente, narração, mas "memória das coisas humanas" (I8r), e, sendo assim, “não somente (...) se escreve a história, mas também se esculpe e se pinta" (I4r). Quanto ao relato historiográfico, especificamente, é considerada uma grande variedade de gêneros, que vai da história universal à biografia, do sermão ao provérbio. Tais histórias podem ser gerais 
ou particulares, ou ainda se combinarem numa infinidade de associações possíveis. Patrizi apresenta, desse modo, um amplo elenco de autores e obras antigos, indicando a enorme diversidade da matéria histórica, assim como a dificuldade de agrupá-la sob um denominativo comum. O ponto central do diálogo, que abre espaço para esta gama de citações, é uma fala em que propõe, em caráter provisório, uma definição da História como sendo "narração dos efeitos que caem sob a percepção dos sentidos e, sobretudo, dos olhos" (8v). Chegara a tal formulação, buscando estabelecer a diferença entre as funções do filósofo e do historiador: uma vez que o filósofo se empenha em descobrir as causas "das coisas que, no mundo, acontecem todos os dias" (7v), o historiador deve saber narrar os efeitos.

Contudo, os efeitos só podem ser apreendidos pelos sentidos, conclusão a que Patrizi chega a partir da etimologia da palavra "história", fornecida por meio de duas interpretações. $\mathrm{Na}$ primeira, afirma que "algum eminente grego formou 'história' a partir do verbo Ido, que quer dizer 'vejo', porque os efeitos são tão somente aquilo que incide sobre os sentidos. E 'vejo' está aqui por 'sinto'. E, segundo ele, 'história' quer dizer, tanto na própria origem quanto em italiano, 'sentido"' (8r). Há quem sustente, porém - e esta é a segunda interpretação -, que

oroo e orao são, naquela língua, verbos que significam, como na nossa, 'vejo'. E a partícula is quer dizer "em", a qual, antepondo-se àqueles, os torna isoroo e isorao. De onde, depois, com algum acréscimo e com alguma mutação, Istoreo se forma, que aos outros dois equivale e significa 'com os próprios olhos vejo dentro da coisa' $(8 \mathrm{r})^{6}$.

Há uma consonância desta ideia com aquela que vimos exposta no primeiro diálogo, pelo modo como Patrizi privilegia o processo da investigação: no primeiro caso, pela ênfase dada ao exame do conceito e, aqui, pela necessidade de discernimento do objeto. Tais procedimentos formam a base de seu método de abordagem e tendem a se unir nos diálogos subsequentes. Assim, se no primeiro diálogo a fonte é Platão, no segundo Patrizi reelabora um topos de enorme fortuna desde a Antiguidade, tendo como modelo Tucídides, que

\footnotetext{
${ }^{6}$ Para reforçar esta elaboração gradual de uma predominância da visão sobre os demais sentidos, Patrizi acrescenta que "os olhos são instrumentos do saber, mais que qualquer outro sentido que o homem possua" (8r).
} 
acreditamos ser o inominado "homem grande e reputado", para quem "a história é a narração que alguém faz das coisas que com os próprios olhos viu" (8r).

Talvez a fonte mais antiga desta ideia esteja em Heráclito, no fragmento DK22B IоIa: "testemunhas mais precisas são os olhos do que os ouvidos". Aqui, com o advento da noção de logos, desaparece a figura do poeta como intermediário entre as Musas e os homens, numa chave homérica ${ }^{7}$, embora com isso, o filósofo não pareça franquear a todos o acesso à verdade, se compreendemos de fato o que diz o fragmento Io7: "Maus testemunhos são para os homens olhos e ouvidos se almas bárbaras eles têm”. É preciso saber ver.

Está aberto, assim, o caminho para várias reelaborações desta ideia. No campo da historiografia, Tucídides parece ser o primeiro a produzir um juízo sobre ela. Primeiramente, rompe com a interpretação tradicional do passado, estabelecendo uma metodologia mais rigorosa quanto aos procedimentos da pesquisa com vistas à reconstituição histórica: "A tal ponto é negligenciada a pesquisa da verdade pela maioria dos homens que se inclinam de preferência para a versão corrente" (História da Guerra do Peloponeso, I. 20.3).

Em consequência disto, busca separar sua obra daquelas produzidas anteriormente por poetas e logógrafos ${ }^{8}$. Heródoto, de quem tenta se distanciar, mas cuja obra conhecia em detalhes (Finley, I989, p. II), havia estabelecido os princípios de uma operação historiográfica fortemente fundada sobre a ideia de investigação (historíe), o que determina que, "daí em diante, para 'ver' é preciso arriscar-se (ir ver) e aprender a ver (recolher testemunhos, reunir as diferentes versões, relatá-las, classificá-las em função do que se sabe por outras fontes e também em função do grau de verossimilhança)" (Hartog, 200I, p. 5I). Contudo, sua investigação ainda se pauta bastante na tradição oral, nos poetas da idade arcaica e nos indícios e evidências que chegaram até seu tempo. Viu muito, mas também lhe era indispensável ouvir.

\footnotetext{
${ }^{7}$ Em Homero (por exemplo, no prólogo que antecede o Catálogo das Naus, na Ilíada II.484-493) percebe-se duas esferas distintas (ou níveis) de conhecimento: a das Musas e a dos homens, sendo que a última se define como um pseudo-saber, o saber de quem não vê, mas apenas ouve, os rumores da fama ("nós, nada mais sabendo, só a fama ouvimos"). Quem conhece a verdade são as musas, pois, "moradoras do Olimpo", a tudo têm acesso ("todo-sapientes"), em qualquer lugar que seja ("todo-presentes"). A única forma de elevação à verdade consiste em o aedo fazer-se inspirar por estas divindades e, agindo como um instrumento, comunicá-la aos homens. Deste modo, o aedo, embora cego, "vê o que todavia jamais viu e se "lembra" do que, para ser exato, jamais conheceu" (Hartog, 200I, p. 34).

8 "Com base nos indícios que foram enunciados, entretanto, não erraria quem, de modo geral, julgasse dessa maneira aquilo que eu expus e não desse crédito maior nem ao que fizeram os poetas adornando seus hinos com o intuito de engrandecê-los, nem ao que os logógrafos compuseram visando ao que é mais atraente para o auditório de preferência ao que é verdadeiro, pois não é possível comprovar esses fatos e a maioria deles, sob a ação do tempo, ganhou um caráter mítico que não merece fé" (História da Guerra do Peloponeso, I.2I).
} 
A ruptura de Tucídides com o modelo herodotiano também se manifesta na sua decisão de escrever a história contemporânea, a única história "verdadeira" possível de ser escrita, tendo em vista, por outro lado, a impossibilidade de uma história 'científica' do passado. Prepara, assim, o terreno para o cabal predomínio da noção de autopsía - a experiência direta, "ver com os próprios olhos", - sobre a informação obtida por meio de relatos de testemunhas ou por outras formas orais de transmissão.

Um exemplo desta ideia se encontra no terceiro livro da História da Guerra do Peloponeso, na passagem em que o autor descreve a retomada da discussão em torno do destino dos habitantes de Metilene, após terem sido previamente condenados pela malograda revolta contra Atenas:

Admiro-me também daquele que me responderá e tentará provar que os crimes nos beneficiam, mas nossos infortúnios são prejudiciais aos nossos aliados. Evidentemente ele tem tanta confiança no poder de suas palavras que vai tentar demonstrar que vossa resolução unânime não foi aprovada, ou então, incitado pela cobiça, esforçar-se-á por achar palavras suficientemente especiosas para vos enganar. Em torneios desse tipo a cidade concede os prêmios a outros, guardando para si apenas os riscos. E a culpa é vossa; sois maus organizadores desses torneios, pois preferis ser espectadores de palavras e ouvintes de fatos, decidindo sobre ações futuras de conformidade com a versão de hábeis oradores interessados em apresentá-las como factíveis, e vendo fatos consumados à luz de críticas brilhantemente formuladas, dando assim mais crédito à versão que ao acontecimento visto com vossos próprios olhos (História da Guerra do Peloponeso, III.38.I-4)

Assim, dentro do sistema epistemológico de Tucídides, conforme a síntese enunciada por Hartog (200I, p. 99),

dos dois meios de conhecimento histórico, o olho (ópsis) e o ouvido (akoé), só o primeiro pode conduzir a uma visão 'clara e distinta' (saphôs eidénai). É preciso ainda saber usá-lo: a autópsia não é um dado imediato da consciência. Convém filtrá-la de acordo com todo um procedimento de crítica dos testemunhos. O ouvido, por sua parte, não é jamais seguro, a 
memória esquece, deforma ou cede à lei do prazer que pauta a boca pela orelha. É por isso que não há história 'científica' senão do presente.

Uma leitura atenta de passagens de diálogos posteriores não deixa dúvidas de que Patrizi também o aceita plenamente. No sétimo diálogo, em que o assunto em pauta é a interpretação das ações humanas, o filósofo nos apresenta uma imagem um tanto espirituosa ao afirmar que toda "ação é envolta em mil invólucros, à guisa de uma cebola" (39r). O historiador deveria ser, portanto, um "mestre anatomista de cebolas", para "descascar, um a um, estes envoltórios" que são o tempo, o lugar, o modo, o instrumento, a razão, entre tantos outros desdobramentos destes elementos constitutivos da ação. Anteriormente, havia afirmado que o acesso a todos eles só é possível quando se toma para análise os acontecimentos contemporâneos e, ainda assim, somente aqueles a que se pode presenciar, pois os príncipes e os poderosos têm sempre junto de si sua mais doce serva, a Fama. Figura "com freqüência contrária a si mesma", dizendo "aqui uma coisa e outra acolá" (26v), a Fama "faz engolir o vento da verdade" (28v).

É fácil reconhecer nestas imagens o descrédito por aquilo que se ouve (a Fama que espalha mentiras, calando a verdade) e a legitimidade daquilo que se vê (o historiador como "anatomista" de ações), elementos caros a esta concepção de matriz tucididiana.

Assim, como foi visto, a adoção do princípio de que a matéria histórica envolve todos os fenômenos passíveis de escrutínio pelos sentidos leva Patrizi a ampliar de tal modo o campo da historiografia, que não causa surpresa o fato de os interlocutores dos primeiros diálogos chegarem, no final, a um estado de aporia. Segundo Vasoli (1989, p. 53),

O “tão tenebroso Labirinto" que emerge por meio da análise da infinita "matéria" histórica não apenas condena definitivamente as opiniões de Luciano, mas revela o quanto é difícil individuar uma definição que ponha ordem na desmesurada selva do discurso "histórico" e de uma "narração" que deveria coincidir com a indefinível medida do mundo e a insondável "variedade" da natureza e dos acontecimentos humanos.

A única forma vislumbrada pelo filósofo de sair deste "Labirinto" seria, em afinidade com seus contemporâneos Telésio e Bruno, abarcar esta "História Menor" numa "História do Mundo Maior", em que as vicissitudes humanas estão sujeitas a leis que regem o universo, 
contrapondo, assim, uma visão cósmica do destino humano a um "discurso concebido substancialmente nos termos do ensinamento ético-político e conduzido com o instrumento do exemplum" (Vasoli, I989, p. 54). Aqui, também, a visão recebe uma posição de destaque, embora dentro de uma outra perspectiva.

IV

A partir do terceiro diálogo, Il Contarino overo che sia l'historia, Patrizi tenta organizar metodicamente a enorme variedade da matéria histórica que emerge dos diálogos anteriores, em um esquema que a contemple inteiramente e que, necessariamente, deva sair do âmbito restrito da Retórica. Já estabelecera, portanto, as condições essenciais para propor que a História seja (re)conduzida ao campo da Filosofia. Não por acaso, todo o diálogo é construído sob o signo do delírio, com claras alusões a passagens do Fedro e do Político, de Platão. Patriziprotagonista, em estado febril, perscruta "o livro da minha alma” (I2r) - para surpresa de seus amigos que, a princípio, acreditavam que ele "delirasse", e só depois percebem que está "sob os delírios de Platão" -, tentando encontrar "que coisa seria a História"9 (I2v). À pergunta de Giorgio Contarini sobre a possibilidade de encontrar a resposta em "livros alheios", sem que fosse necessário recorrer ao da alma, Patrizi afirma que "todas as coisas que vejo nos livros de fora, [...] vou procurando também no livro da minha alma, no qual muitas encontro e muitas, não [...]. E aquelas que encontro, estimo que sejam verdadeiras, e aquelas que não, estimo serem falsas" (I2V-I3r).

Ainda seguindo o Fedro, percebemos ser esta uma leitura sucinta do discurso de Sócrates acerca dos efeitos da beleza na alma humana, que culmina com a afirmação de que a visão é o mais agudo dos sentidos, embora não possa, por si só, perceber a sabedoria (Fedro, 250d). É forte a ideia de se submeter ao escrutínio da razão (inteligência) as imagens belas que se vê no mundo.

Tampouco escapa a Patrizi o lugar de destaque que a memória ocupa no segundo discurso de Sócrates, representando o mundo das formas perfeitas, a recordação destas e o

\footnotetext{
${ }^{9}$ Ao longo do diálogo, fica cada vez mais claro que trata-se da representação do quarto tipo de delírio que Platão expõe no Fedro, aquele em que alguém, quando neste mundo vê beleza, "recorda-se então da beleza verdadeira, recebe asas e deseja voar para o alto; não o podendo, porém, dirige o olhar para cima esquecendo os negócios terrenos e dando, desta maneira, a impressão de delirante. De todos os entusiasmos este é o melhor e da mais perfeita origem" (Fedro, 249d-249e).
} 
limitado acesso que a elas se tem por meio da metáfora do livro que "fala sobre todas as coisas [...] [tendo sido] escrito pela mão de Deus" (I2r). Primeiramente, trata-se de um livro escrito numa linguagem universal (e, como se observa, divina), acima e diversa de toda linguagem humana ${ }^{\mathrm{IO}}$ :

"De que forma [é escrito este livro]?" "Por imagens, como os livros daqueles que vivem no Japão e na China, que os entendem pelas escrituras, e não pelas palavras. [...] Cada letra [...], naqueles livros de lá, quer dizer uma coisa. Assim, uma imagem de Ideia, que é escrita nos livros das almas de todos os homens, se faz entender aos homens de todas as línguas" (I2v).

Em segundo lugar, tal linguagem pode ser revelada somente por meio do furor ou delírio. Disto, o próprio estado de espírito do protagonista ao longo de todo o diálogo busca nos persuadir. Por fim, o que pode ser dito em relação às diferenças existentes entre os livros "exteriores", posto que são escritos "conforme o exemplo daquele de dentro" (I3r), que, por sua vez, pode ser compreendido por todos os homens? Neste ponto, ganha destaque o papel da memória:

Os livros da alma têm os seus caracteres em relevo e é possível descortiçá-los de parte em parte e, como se lhes traçasse a anatomia, penetrar até a sua íntima medula. E como a alma possui, dentro de si, este livro, ele não pode ser visto por aqueles que não a veem, pois havendo inúmeros homens que sempre olham para fora e nunca voltam o olhar para si mesmos, é impossível que saibam ter em si esta escritura, feita pela divina mão de Deus. E se estes tais se dão a escrever, fazem os seus livros sobre aquelas coisas que viram nos corpos fora de si mesmos. Há também aqueles que, olhando para dentro de si, veem o livro que vos digo, mas, ou não cuidam de consultá-lo, ou não penetram mais do que a primeira ou a segunda camada, e disto nasce a diversidade dos livros exteriores (I3r) $)^{\mathrm{II}}$.

\footnotetext{
${ }^{10}$ Há, nesta passagem, uma implícita refutação do pensamento de Sperone Speroni e de outros membros das academia paduana dei Infiammati, para os quais, seguindo os pressupostos avançados por Pomponazzi, toda língua humana tem a capacidade de expressar as imutáveis verdades filosóficas.

${ }^{\text {II }}$ A passagem pode ser comparada com o seguinte fragmento do Fedro, 249e-250a: "a alma humana, dada a sua própria natureza, contemplou o Ser verdadeiro. De outro modo nunca poderia animar um corpo humano. Mas as lembranças desta contemplação não despertam em todas as almas com a mesma facilidade. Uma apenas entreviu
} 
Extremamente significativa, portanto, esta passagem em que o filósofo subordina todos os "livros de fora" - e aí a alusão aos "livros" anteriormente mencionados é evidente - ao "livro da alma". A partir daí, suas reflexões "tendem a 'ultrapassar' a dimensão histórica e a colocar-se sobre um plano metafísico" (Bolzoni, 1980, p. 67). Esta busca filosófica encerra uma forte convicção na possibilidade de uma comunicação perfeita entre o homem e Deus e de uma recuperação do vínculo entre palavra e coisa, que será a proposta central dos seus Dialoghi della retorica. A leitura do "livro da alma", sob o signo do furor, único meio de guiar a disposição intelectiva do homem ao conhecimento da verdade, possibilita entender o modo como a história humana (minore) insere-se numa dimensão cósmica (Historia del magior mondo). Isto Patrizi faz através do relato de um mito: o "das corrupções do mundo e seus renascimentos" (I5r). Entramos, assim, numa leitura muito pontual de alguns temas tratados no Político e no Timeu. Para sermos mais específicos, o relato patriziano pode ser considerado uma paráfrase das seções $269 \mathrm{c}-270 a, 272 \mathrm{~d}-274 \mathrm{e}$ do primeiro e das seções 2Ie-23c do segundo diálogo platônico, em que, de maneira semelhante, o filósofo grego recorre a mitos.

Narrado a um tio de Patrizi por um eremita egípcio, "de idade muito antigo, de vida santíssima e de profunda ciência" ( $15 \mathrm{r}$ ), o mito representa o Egito como "templo de todo o mundo e imagem do céu, [...] [que guarda] a memória de duas corrupções universais e de dois universais renascimentos de toda a máquina do mundo." Tais corrupções são causadas por acidentes naturais (pestes, dilúvios, incêndios, etc.), assim como por deliberação humana (como as guerras), que são, por sua vez, "postos em movimento pelos céus, por meio dos astros e dos influxos das estrelas, [...] [pois] as coisas do baixo mundo são, por ocultos meios, governadas pelas celestes e por aquelas ainda mais altas" (15v). De fato, haveria no universo dois movimentos opostos, de ascensão e de declínio ${ }^{\mathrm{I} 2}$, em eterna repetição, para tudo o que nele existe. Assim, para os homens, também existiriam dois grandes momentos que se sucedem eternamente: um em que Deus governa o mundo, trazendo "renovação da vida e da imortalidade" (I7r); e um momento posterior, em que este vínculo se desfaz, Deus se distancia e, por um desordenamento dos astros, tais catástrofes se sucedem, inaugurando uma era

o Ser verdadeiro; outra, após a sua queda, movida pela iniquidade, esqueceu os mistérios sagrados que um dia contemplou. Portanto, são poucas as almas cuja recordação é bastante clara. [...]"

${ }^{12}$ Como em Platão, os movimentos são circulares: "Este universo, em que estamos, algumas vezes é o próprio Deus que lhe dirige o curso e preside à sua revolução; outras vezes, terminados os períodos que lhe foram determinados, ele o deixa seguir; e então, por si mesmo, o Universo retoma o seu curso circular, em sentido inverso, em virtude da vida que o anima e da inteligência que lhe foi dada, desde a sua origem, por aquele que $o$ criou" (Político, 269c-269d). 
dominada pela corrupção e pelo medo. Portanto, estas revoluções, embora sejam universais, "não corrompem por completo todas as linhagens dos homens, [...] [porque] é necessário que estáveis e incorruptos restem, de todas as espécies, aqueles indivíduos apenas os quais bastem para conservar o mundo corporal, conforme seu exemplo" (I6r). Os poucos sobreviventes, coagidos a buscar refúgio nas florestas e montes, lentamente vão se unindo em pequenos grupos. O abrigo encontrado no interior da pequena comunidade causa uma sensação de conforto que, a todo o custo, buscam manter e até mesmo aumentar. Daí começam a surgir todos os elementos constitutivos de uma civilização, como as técnicas, a arte, a religião e as formas de convívio social, que se prolongarão por um tempo, até que, novamente corrompidos os costumes, "do tudo em nada se desfaçam"’3.

Portanto, é neste estágio de decadência que se insere a história humana, embora ela possa compreender também o empenho do homem em recuperar a perfeição de sua condição originária. Esta ideia parece conduzir a uma certa ambivalência, e disto nos dão provas algumas passagens dos Dialoghi. Às vezes, Patrizi nos fornece indícios de um total ceticismo quanto a uma intervenção humana positiva neste processo marcado por uma visão tão fatalista. Outras vezes, demonstra ter confiança na noção do homem de virtù, capaz de conduzir a si mesmo e sua comunidade a um estado de felicidade, apesar das adversidades da fortuna. Destas duas visões, esta última se resolve na esfera da "história do mundo menor", dentro dos limites da política. A primeira, obviamente, não se resolve. É uma visão trágica, que se pauta na conviç̧ão de que não há força que altere este movimento de ascensão e declínio. Cabe-nos esclarecer como se constitui este juízo negativo sobre a vida civilizada e como ela mesma serve de fundamento para a recuperação do vínculo originário. Esta questão liga o mito que agora abordamos a um outro, exposto no primeiro dos Dialoghi della retorica, onde ela recebe uma elaboração mais aprofundada.

O mito teria sido relatado por Baldassare Castiglione a Giulio Strozzi, interlocutor de Patrizi. Castiglione, portanto, veio a saber, por parte de um sábio etíope, que

\footnotetext{
${ }^{13}$ Outro ponto em que Patrizi sutilmente diverge de Platão é apontado por Plastina (1992, p. 3I): Há "um tipo de deslocamento da conhecida concepção que se pode ler nas entrelinhas do Político (27Ic), onde Platão parece firmar um juízo bastante negativo sobre esta condição primitiva, considerada quase igual à das bestas: os homens da primeira antiguidade estavam sob o poder dos deuses, da mesma forma como agora são os homens que conduzem ao pasto os outros animais, 'mais estultos que eles'; enquanto a interpretação que Patrizi faz [...] parte de um ângulo diferente: somente depois da 'queda', os homens sobreviventes, reorganizando-se sob o impulso do medo, ofuscados pela ignorância, por certo se assemelham mais às bestas."
} 
nos primeiros séculos [...] depois da última renovação do mundo, esta terra em que habitamos [...] era muito maior, e de perfeita rotundidade. [...] Estava [...] muito próxima do céu, e tanto em seu interior como na superfície, era cavernosa, com cavernas muito largas (Patrizi, 1562, p. 5v).

A Terra se assemelhava a uma esponja, e os homens habitavam tanto seu interior quanto as partes mais próximas à superfície. E a vida humana era perfeita e feliz: "não havia, entre os homens, nem guerra, nem sedição, nem ódio algum". Tampouco viviam em cidades, pois não tinham motivo para temer as feras, que com eles conviviam harmoniosamente, e não tinham necessidade de nada, pois, "tendo ciência interna das coisas, falavam com nitidez, e [...] operavam maravilhas e milagres". Conheciam "todas as verdades e todas as virtudes de todas as coisas, sabiam que todas eram boas e que não havia nada ruim” (Patrizi, I562, p. 6r), e com familiaridade conversavam com "os animais, com os pássaros, com as plantas e com os espíritos”, principalmente aqueles homens que viviam na superfície, próximos aos céus, os quais, "para além do éter claríssimo, divisavam todas as virtudes de todas as estrelas, e seus sentidos, nutrindo-se no éter puríssimo, eram puríssimos".

Entre estes homens que viviam nas regiões mais elevadas da Terra, encontravam-se os assírios que, "operando as maravilhas, disto se comprouveram mais do que deviam" e, nascendo, com isto, o amor próprio, começaram a pensar em si mesmos como deuses. A princípio, Saturno "privou-lhes dos influxos de sua mente", o que fez com que se tornassem ainda mais orgulhosos, ignorantes e insolentes, buscando uma forma de subirem ao céu para tomar o controle do mundo. O deus, então, renunciou o governo a seu filho, Júpiter, que, auxiliado pelo irmão, Plutão, pôs termo à desmedida humana. O primeiro fulminou o mundo, enquanto o outro fez com que a Terra, abalada em suas raízes, ruísse horrivelmente, tornando-se menor. Os homens que viviam mais próximos do centro morreram soterrados. Dos outros, a maioria morreu atemorizada. Pouquíssimos foram os sobreviventes, a quem as setas de Júpiter feriram de longe, não por outro motivo, senão "para que restasse algum vestígio da primeira forma do mundo" (Patrizi, 1562, 6v-7r). Estes, a princípio caíram desfalecidos e, após recuperarem-se do abalo, "permaneceram sempre aturdidos e cheios de um horrendo temor". Ao se encontrarem pelo mundo, se abraçavam e passavam a viver juntos, pela "doçura da lembrança de sua felicidade anterior, e também pelo temor que provaram, parecendolhes que estivessem mais seguros entre seres da própria linhagem, do que se estivessem com 
outras espécies confundidos". Seus filhos herdaram este temor, tornando-o ainda maior, tanto em relação à natureza quanto a si mesmos.

A cidade, portanto, nasce deste temor e da necessidade de auto-preservação. Os homens agora vêem as coisas através de um véu, e as gerações mais novas entendem o conhecimento da verdade como a causa da ruína de seus antepassados. E, neste ponto, podemos compreender melhor como, para Patrizi, a vida civilizada forja uma linguagem nascida do medo e da ambição pelo poder e, portanto, enganosa. Ela surge juntamente com a técnica e com as artes, para o engano e a opressão dos mais fracos e, quando alguém, "por acaso", descobre alguma verdade e queira manifestá-la

para que, por ela, não seja pelos outros censurado, vituperado ou acerbamente punido, por temor que, pela descoberta da verdade, maior infelicidade lhes acontecesse, de mil modos a encobre. E, assim, as ciências são ensinadas através de enigmas, fábulas, figuras, números, e mil outros modos velados, em sacrários, sob silêncio (Patrizi, 1562, 7r).

A leitura destes mitos comprova a afinidade de Patrizi com a ideia de uma prisca sapientia que, conforme a doutrina hermética, se originara no Egito e fora secretamente transmitida. E, de fato, o mito relatado no terceiro diálogo della Historia termina com a afirmação de que o Egito manteve-se incólume ao fim das duas últimas revoluções porque, "no incêndio, somos defendidos pelo Nilo, e dilúvios, jamais chovendo por aqui, não tememos" (I6v). A memória de tais corrompimenti foi inscrita num dos lados de uma coluna sagrada, que trazia, noutro lado, marcas, ainda mais antigas, das inundações do Nilo. Estas marcas serviam para a previsão de anos de fartura ou privação, conforme "o crescimento das águas”.

Patrizi conclui que "a história começou a escrever-se no Egito; não sobre os feitos dos homens, mas sobre as cheias e as inundações do Nilo [...] [como] memória dos efeitos daquela água" (I4r). Portanto, a primeira "história" que surgiu não foi escrita, mas "esculpida", e versava sobre coisas futuras, o que leva o filósofo a incluir a profecia no campo da história, alargando-o ao extremo, assim como havia feito com seu objeto, como foi visto anteriormente. E o diálogo se conclui com a recusa da noção de história como narração 
apenas, buscando englobar todos estes novos elementos na definição de que "a história é memória das coisas humanas".

Rejeitar aquilo que se ouve, compreender aquilo que se vê. Cremos que esta fórmula possa sintetizar as proposições de Patrizi nestes primeiros diálogos de sua obra, que lançam uma espécie de base epistemológica de suas reflexões sobre a história. Partindo da crítica (às vezes velada) a modelos historiográficos calcados em pressupostos retóricos, a partir dos quais a história se torna "uma espécie de poesia em prosa", para usarmos a clássica definição de Quintiliano (Institutionis oratoriae XII, X,I,3I), o filósofo vai, aos poucos, direcionando sua argumentação para uma concepção em que prepondera o princípio da análise. Autêntico é aquilo que se mostra à nossa percepção. A experiência deve ser objeto de investigação. Por isto, o deslocamento daquilo que se ouve (lembremos da figura da Fama, serva de príncipes) para a legitimidade do que é visto.

\section{Referências Bibliográficas}

BOLZONI, Lina. L'universo dei poemi possibili - studi su Francesco Patrizi da Cherso. Roma: Bulzoni, 1980.

CICERO. De Inventione, De optimo genere oratorum, Topica. Trad. Harry M. Hubbell. The LOEB Classical Library. London: William Heinemann Ltd, 949. Orator. The LOEB Classical Library. London: William Heinemann Ltd, 1988.

[CICERO]. Rhetorica ad herennium. Trad. Harry Caplan. LOEB Classical Library. Cambridge: Harvard University Press, I954.

FINLEY, M. I. Mito, Memória e História. In Uso e Abuso da História. São Paulo: Martins Fontes, I989.

HARTOG, François. A História de Homero a Santo Agostinho. Trad. Jacyntho Lins Brandão. Belo Horizonte: Editora UFMG, $200 \mathrm{I}$.

HERÓDOTO. História: O Relato Clássico da Guerra entre Gregos e Persas. Trad. J. Brito Broca. Rio de Janeiro: Ediouro, 200I.

HOMERO. Ilíada. Trad. Haroldo de Campos. São Paulo: Arx, 2002.

LUCIAN. The Way to Write History. [on line] 2002. Disponível: www.abacci.com/books. 
MORAES, Helvio. Accademia della Fama: Atividade Literária, Projeto editorial e Política na Gênese dos Diálogos da História de Francesco Patrizi, Revista Ecos (Cáceres), v. IO, 201 I.

NAGY, Gregory. The First Song of Demodokos. In The best of the Achaeans: Concepts of the Hero in Archaic Greek Poetry. Baltimore; London: J. Hopkins University, 1990.

PATRIZI, Francesco. Della historia diece dialoghi di M. Francesco Patritio ne' quali si ragiona di tutte le cose appartenenti all'historia, E allo scriverla, E all'osservarla. Venetia, MDLX. . Della retorica dieci dialoghi di M. Francesco Patritio. [on line] 2003 [I562]. Disponivel: www.bivionline.it.

PLASTINA, Sandra. Gli alunni di Crono - Mito linguaggio e storia in Francesco Patrizi da Cherso (I529-I597). Messina: Rubbettino Editore, I992.

PLATÃO. Fedro. Trad. Jorge Paleikat. Rio de Janeiro: Ediouro, 1999. . Phaedrus. [on line] Disponível: http://www.perseus.tufts.edu . Político. In Os Pensadores. Trad. Jorge Paleikat e João Cruz Costa. São Paulo: Nova Cultural, 1987.

. Timaeus. [on line] Disponível: http://www.perseus.tufts.edu

ROGUE, Christophe. Compreender Platao. Petropolis: Editora Vozes, 2005.

TUCÍDIDES. História da Guerra do Peloponeso. Trad. Mário da Gama Kury. Brasília: Editora Universidade de Brasília, Instituto de Pesquisa de Relações Internacionais; São Paulo: Imprensa Oficial do Estado de São Paulo, 200I.

VASOLI, Cesare. Alle origini della crisi delle "tradizioni”: Francesco Patrizi e la cultura veneta degli anni sessanta. In: BRANCA, Vittore \& OSSOLA, Carlo (ed.). Crisi e rinovamenti nell'autunno del Rinascimento a Venezia. Firenze: Leo S. Olschki, I99I. . Francesco Patrizi da Cherso. Roma: Bulzoni, 1989. 